\title{
The integrated multiomic diagnosis of sporadic meningiomas: a review of its clinical implications
}

\author{
Stephanie M. Robert ${ }^{1}$. Shaurey Vetsa ${ }^{1,2} \cdot$ Arushii Nadar $^{1,2} \cdot$ Sagar Vasandani $^{1,2} \cdot$ Mark W. Youngblood $^{3}$. \\ Evan Gorelick $^{1,2} \cdot$ Lan Jin $^{1} \cdot$ Neelan Marianayagam ${ }^{1,2} \cdot$ E Zeynep Erson-Omay $^{1,2} \cdot$ Murat Günel $^{1,2}$. \\ Jennifer Moliterno ${ }^{1,2}$ (1)
}

Received: 24 August 2021 / Accepted: 9 October 2021, / Published online: 30 November 2021

(c) The Author(s) 2021, corrected publication 2021

\begin{abstract}
Introduction Meningiomas are generally considered "benign," however, these tumors can demonstrate variability in behavior and a surprising aggressiveness with elevated rates of recurrence. The advancement of next-generation molecular technologies have led to the understanding of the genomic and epigenomic landscape of meningiomas and more recent correlations with clinical characteristics and behavior.

Methods Based on a thorough review of recent peer-reviewed publications (PubMed) and edited texts, we provide a molecular overview of meningiomas with a focus on relevant clinical implications.

Results The identification of specific somatic driver mutations has led to the classification of several major genomic subgroups, which account for more than $80 \%$ of sporadic meningiomas, and can be distinguished using noninvasive clinical variables to help guide management decisions. Other somatic genomic modifications, including non-coding alterations and copy number variations, have also been correlated with tumor characteristics. Furthermore, epigenomic modifications in meningiomas have recently been described, with DNA methylation being the most widely studied and potentially most clinically relevant. Based on these molecular insights, several clinical trials are currently underway in an effort to establish effective medical therapeutic options for meningioma.

Conclusion As we enhance our multiomic understanding of meningiomas, our ability to care for patients with these tumors will continue to improve. Further biological insights will lead to additional progress in precision medicine for meningiomas.
\end{abstract}

Keywords Meningioma $\cdot$ Sporadic $\cdot$ Genomic subgroups $\cdot$ Precision medicine

\section{Introduction}

Meningiomas are the most common primary central nervous system (CNS) tumor, accounting for $\sim 40 \%$ of intracranial tumors and $54 \%$ of nonmalignant tumors [1,2]. While the majority are slow growing, when intervention is necessary due to size and/or symptomatology, treatment involves neurosurgical resection. Radiotherapy is used more variably and

Jennifer Moliterno

jennifer.moliternogunel@yale.edu

1 Department of Neurosurgery, Yale School of Medicine, 15 York St, LLCI 810, New Haven, CT 06520-8082, USA

2 The Chenevert Family Brain Tumor Center, Smilow Cancer Hospital, New Haven, CT, USA

3 Department of Neurological Surgery, Northwestern University, Chicago, IL, USA despite significant advancements in our understanding of meningioma biology, there remains no effective pharmacological therapies.

Typically considered "benign," meningiomas are defined by location and histology. Classified based on atypical features, including mitoses and brain invasion, they are divided into three World Health Organization (WHO) grades. Grade I ( $~ 80 \%$ of meningiomas) demonstrate low risk of recurrence; grade II (atypical) and grade III (anaplastic) exhibit higher rates of growth, with the latter being frankly "malignant" and demonstrating recurrence rates $>70 \%$ after gross total resection [3]. There are 15 histological subtypes, with nine variants recognized in grade I tumors [4]. These tumors do not, however, always behave according to their WHO grading, with reports of histologically-confirmed grade I tumors demonstrating unexpected recurrence, malignant 
transformation, and aggressive behavior [5], underscoring their complexity and heterogeneity.

The last decade has provided insight into meningioma biology, particularly for those arising sporadically. Several recently identified somatic driver mutations have defined new clinically-relevant molecular subgroups [6] and this knowledge has shifted focus to integrated diagnosis, targeted treatment, and novel opportunities for pharmacological development. Importantly, the WHO grading scale has been updated to incorporate molecular diagnostics (see below) [7]. In this review, we discuss our current understanding of the multiomic landscape of meningiomas, with a focus on relevant clinical implications.

\section{Genomic landscape of sporadic meningiomas}

Germline mutations are well-established drivers of meningioma formation, especially those arising in the context of genetic diseases such as neurofibromatosis type II (NF2), Gorlin and Cowden syndromes [8]. Recent focus has turned to characterization of sporadic meningiomas, which account for the majority of these tumors and typically occur without a clear inciting event. Importantly, meningiomas are unique in harboring a small number of somatic mutations, and this "cleaner" genomic architecture has allowed expeditious insight into the pathophysiology of sporadic meningiomas.

\section{Genomic subgroup classification based on key driver mutations}

Major genomic subgroups have been defined based on specific somatic driver mutations in $\sim 80 \%$ of sporadic meningiomas [9]. These include (1) Neurofibromatosis-2 (NF2) with or without co-mutation in SWI/SNF Related, Matrix Associated, Actin Dependent Regulator of Chromatin, Subfamily B, Member 1 (SMARCB1); (2) mutations in the WD40 region of TNF Receptor-Associated Factor 7 (TRAF7), which can occur alone or (3) with a recurrent mutation in Kruppel-Like Factor $4\left(K L F 4^{K 409 Q}\right)$ or (4) mutations in PI3K (phosphoinositide 3-kinase) pathway molecules, including PIK3CA, PIK3RI, and $A K T 1^{E 17 K}$; (5) Hedgehog $(\mathrm{HH})$ signaling molecules (i.e. SMO, SUFU, PRKARIA); (6) recurrent mutations in RNA Polymerase II Subunit A (POL$R 2 A^{Q 403 K}$ or $\left.{ }^{L 438}{ }^{4439 d e l}\right)$, or (7) SMARCE1 mutations [6, 9-11]. Over half of sporadic meningiomas harbor somatic $N F 2$-mutations and noninvasive clinical diagnostics can differentiate between NF2-mutated and non-mutated meningiomas, with important implications for patient care [6]. These genomic subgroup classifications, important somatic driver mutations, and their relationships are illustrated in Fig. 1.

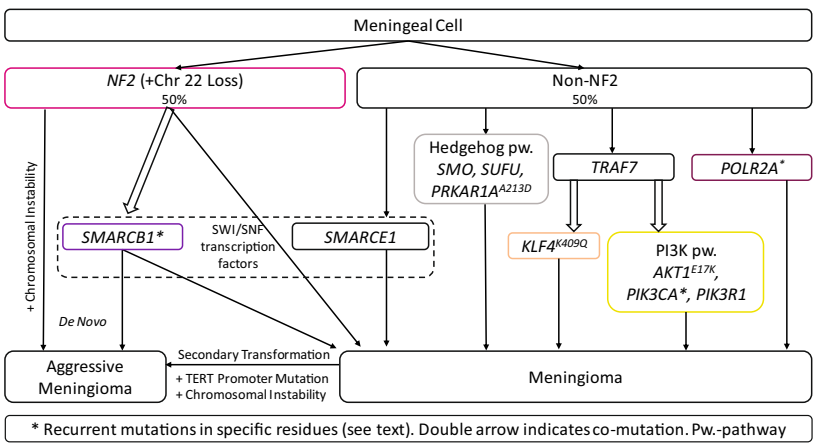

Fig. 1 Somatic mutational profile of sporadic meningiomas

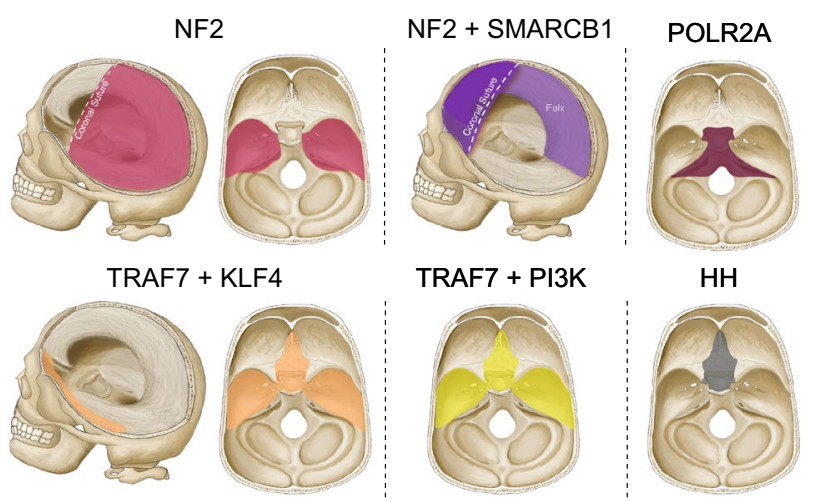

Fig. 2 Localization of molecular subtypes to unique brain regions. Adapted from Youngblood et al., 2019 with permission from the Journal of Neurosurgery [6]

\section{NF2-mutated meningiomas}

The most common driver mutation is biallelic loss of $N F 2$, accounting for $>50 \%$ of meningiomas [12]. A tumor suppressor, $N F 2$ encodes a cytoskeleton scaffold protein involved in cell proliferation and apoptosis. Aggressive NF2-mutated meningiomas acquire chromosomal instability or co-mutation in another tumor suppressor gene, SMARCB1 [13]. Most somatic NF2 mutations are in solitary, sporadic meningiomas, however, they can occur in radiation-induced and multiple meningiomas [14].

NF2-mutated meningiomas demonstrate larger volumes, fibrous or atypical histology, male predominance, and preferentially occur along the cerebral convexities posterior to the coronal suture (Fig. 2) [6, 15]. Along the skull base, NF2-mutant meningiomas show lateral to medial gradient, originating along the lateral sphenoid wing, invading the bone [16]. These mutations are associated with preoperative seizures, predict a more aggressive clinical course, shorter progression free survival [17], and correlate with higher proliferation indexes [6]. They are 
enriched in recurrent tumors, especially when present with recurrent SMARCB1 mutations. SMARCB1, part of the switch/sucrose non-fermentable (SWI/SNF) chromatinremodeling complex protein [18], demonstrates recurrent p.Arg383Gln or p.Arg386His mutations [18-20]. Unlike NF2-mutated meningiomas, SMARCB1/NF2 co-mutations localize anterior to the coronal suture and medially along the falx [18].

\section{Non-NF2 mutated meningiomas}

TRAF7 is the most common somatic mutation in non-NF2 meningiomas, present in $\sim 25 \%$ of sporadic tumors [10]. As a proapoptotic E3 ubiquitin ligase, TRAF7 activates downstream signaling pathways including mitogen-activated protein kinase (MAPK) and nuclear factor-kB (NF-kB), with mutations causing unregulated NF-kB activity and cell proliferation [10, 13]. TRAF7 tumors demonstrate meningothelial histology and higher-grade characteristics $[6,18]$. Mutations in the KLF4 or PI3K pathway, such as $A K T 1$ or PIK3CA, co-occur with TRAF7. Mutations in KLF4, a zinc finger transcription factor, affect the specific lysine residue at position $409\left(K L F 4^{K 409 Q}\right)[10,21]$. TRAF/KLF4 ${ }^{K 409}$ mutations are found in $\sim 10 \%$ of meningiomas, are typically located along the lateral skull base (Fig. 2), demonstrate secretory histology, and cause significant peritumoral edema $[6,10]$. TRAF7 with co-mutations in PI3K/AKT pathway represent an additional $\sim 10 \%$, and localize along the sphenoid wing and medial anterior skull base [11]. Most common is a recurrent $A K T 1^{E 17 K}$ mutation, resulting in constitutive activation of PI3K/mTOR (mammalian target of rapamycin) pathway and upregulation of growth factorinduced cellular survival [6]. PIK3CA, PIK3R1, and AKT3 mutations similarly increase PI3K/AKT signaling and are found in $20 \%$ of anterior skull base or convexity meningiomas (Fig. 2) [6, 9]. Recent data demonstrates that sphenoid wing meningiomas causing hyperostosis are associated with TRAF7 variants [16].

Hedgehog $(\mathrm{HH})$ is another important signaling pathway in meningioma formation. Proteins in this pathway direct developmental patterning and cell differentiation during embryogenesis, and in adult tissues, regulate stem-cell mediated cell cycle activation and tissue regeneration [10, 11]. Mutations Smoothened (SMO) and Suppressor of Fused $(S U F U)$ genes are the most common, are associated with meningothelial and low grade histology [22], and occur in the anterior skull base, typically midline along the olfactory groove or planum sphenoidale; $45 \%$ of midline meningiomas demonstrate $\mathrm{HH}$ pathway mutations [23]. Given $\mathrm{HH}$ pathway's role in embryonic midline patterning, these findings underscore the importance of developmental and regulatory gene dysfunction in meningiogenesis.
Recurrent somatic mutations in $P O L R 2 A$ are found in $\sim 6 \%$ of meningiomas [9]. POLR2A encodes RPB1, a member of the polymerase II complex involved in mRNA transcription. Mutations in this enzyme are rare and meningiomas are the only pathology known to harbor these recurrent mutations [9]. POLR2A mutations are thought to alter expression of meningeal progenitor and differentiation genes, including Zic family members 1 and 4 (ZICI/ZIC4) and Wnt family protein 6 and 10A (WNT6/WNT10A) [9]. These tumors are grade I, demonstrate female predominance, meningothelial histology, and occur in the sella, clivus and posterior fossa [6, 9] (Fig. 2).

\section{Other somatic mutations}

Mutations in SMARCE1, another member of the SWI/SNF complex, have been described in higher-grade tumors. SMARCE1 loss is associated with clear cell meningiomas, WHO grade II tumors with elevated recurrence [19, 24]. Additional mutations have been described, including ARIDIA and SMARCA4, with ARIDIA mutations being present in $\sim 20 \%$ of grade I and II tumors, $15 \%$ of grade III meningiomas, and associated with increased mortality [25].

\section{Somatic, non-coding genomic alterations}

As next generation sequencing techniques advance, we are learning the importance of non-coding regions of the genome. The best understood is telomerase reverse transcriptase (TERT) promoter mutations. These mutations, found in $\sim 6 \%$ of meningiomas, cause TERT upregulation, which abnormally extends the telomeres of meningioma cells, enhancing their lifespan [26]. TERT promoter mutations are important in atypical transformation of Grade 1 meningiomas, and are thus found in higher grade, malignant tumors, predicting increased recurrence risk [26].

\section{Somatic copy-number variations}

Copy number variations (CNV), including simple duplications, deletions, or complex rearrangements of genomic regions result in altered transcriptional regulation; tumorigenic CNVs cause deletion of tumor suppressor genes or amplification of oncogenes. The most frequent CNV in sporadic meningiomas is chromosome $22 \mathrm{q}$ deletion, which contains $N F 2$ and SMARCB1, among others [15, 27]. Abnormalities involving Chromosome 1 are also common, with loss of the short arm (1p) being the second most common chromosomal abnormality, found in $70-80 \%$ of atypical meningiomas [28]. In grade I tumors, chromosome 1p deletion increases the risk of recurrence [29] and 1q gain is 
associated with atypical tumors and shorter progression-free survival [28].

Other frequent CNVs include chromosome 9p deletion, which contains tumor suppressor genes Cyclin-Dependent Kinase Inhibitor $2 A$ and $2 B(C D K N 2 A / B)$ [15], and loss of chromosomes 2p, 4p, 6q, 7p, 9p, 10q, 11p, 14q, 17q, and 18q [29-37]. Chromosome $2 p$ loss is associated with choroid meningiomas, while anaplastic meningiomas demonstrate chromosome 1p, 6p, 14, and 22q losses [15]. $C D K N 2 A / B$ mutations are associated with recurrent and aggressive tumors [38, 39], multiple copies of chromosome 5 are found in angiomatous meningiomas [36], gains in chromosome $22 q$ are more often found in skull base regions, while losses at $1 p, 8 p, 14 q$ and $22 q$ correlate with non-skull base locations [33, 40].

Although studies have suggested that grade II/III lesions have more numerous and larger CNVs [29, 33], a recent study demonstrated that while de novo atypical $N F 2$ tumors have more large-scale CNVs, there was no difference between non-NF2 meningioma grades [20]. Chromosome $14 \mathrm{q}$ loss showed the largest difference between atypical and low grade NF2-mutated meningiomas [20].
Furthermore, loss of chromosomes 1, 4p, 10p, 14, and 22, and higher numbers of cumulative CNVs are more common in recurrence [33] (Table 1).

\section{Epigenomic modifications}

The role of epigenomic changes such as aberrant DNA methylation, histone methylation, and acetylation is also being defined [41] (Table 2), with DNA methylation being most well-understood. Hypermethylation of DNA regulatory regions, leading to gene silencing, correlates with tumor aggressiveness and recurrence [20, 42]. Homeobox family genes (HOXA) [43] are often hypermethylated in aggressive tumors, and tumors with a group of five HOXA genes (HOXA6, HOXA9, PENK, UPK3A, and IGF2BP1) hypermethylated together, exhibit higher recurrence rates [44]. Similarly, the genomic locus harboring hypoxia inducible factor (HIF), which inhibits proliferation through angiogenesis regulation, demonstrates increased methylation [45], possibly contributing to tumor growth. Although clear relationships between genomic mutations and epigenomic regulation
Table 1 CNV Associations with meningioma characteristics

\begin{tabular}{|c|c|c|c|}
\hline $\mathrm{CNV}$ & & Known characteristics & Refs. \\
\hline $1 \mathrm{p}$ & $\mathrm{L}$ & $\begin{array}{l}\text { High grade, increased recurrence, non-skull-base location, larger } \\
\text { volume }\end{array}$ & {$[30,33]$} \\
\hline $4 p$ & $\mathrm{~L}$ & Increased recurrence & {$[33]$} \\
\hline $4 q$ & $\mathrm{~L}$ & High grade & {$[37]$} \\
\hline $6 q$ & $\mathrm{~L}$ & High grade, increased recurrence & {$[32,37]$} \\
\hline $8 \mathrm{p}$ & $\mathrm{L}$ & Non-skull-base location & {$[33]$} \\
\hline $9 p$ & $\mathrm{~L}$ & High grade, increased recurrence & {$[30,33]$} \\
\hline $10 \mathrm{p}$ & $\mathrm{L}$ & High grade, increased recurrence & {$[31,33]$} \\
\hline $10 \mathrm{q}$ & $\mathrm{L}$ & High grade & {$[31]$} \\
\hline $11 \mathrm{p}$ & $\mathrm{L}$ & Increased recurrence & {$[33]$} \\
\hline $14 q$ & $\mathrm{~L}$ & High grade, increased recurrence, non-skull-base location & {$[32,79]$} \\
\hline $17 q$ & $\mathrm{~L}$ & Increased recurrence & {$[34]$} \\
\hline $18 \mathrm{q}$ & $\mathrm{L}$ & High grade, increased recurrence & {$[32,79]$} \\
\hline $22 q$ & $\mathrm{~L}$ & High grade, increased recurrence, non-skull-base location & {$[6,36]$} \\
\hline $\mathrm{X}-\mathrm{Chr}$ & $\mathrm{L}$ & High grade & {$[35]$} \\
\hline Y-Chr & $\mathrm{L}$ & High grade & {$[35]$} \\
\hline $1 \mathrm{q}$ & G & High grade & [79] \\
\hline 5 & G & Angiomatous Histology & [36] \\
\hline $9 q$ & $\mathrm{G}$ & High grade & [79] \\
\hline $12 \mathrm{q}$ & G & High grade & [79] \\
\hline $15 q$ & G & High grade & [79] \\
\hline $17 q$ & G & High grade & [79] \\
\hline $20 q$ & G & High grade & [79] \\
\hline $22 p$ & G & Skull-base location & {$[33]$} \\
\hline $22 q$ & G & Skull-base location & {$[33]$} \\
\hline $17 q$ & A & High grade & [30] \\
\hline
\end{tabular}

$G$ gain, $A$ amplification, $L$ loss 
Table 2 Epigenetic changes and associated clinical characteristics in meningioma

\begin{tabular}{|c|c|c|c|}
\hline Epigenetic alteration & Associated meningioma characteristics & Genes & Refs. \\
\hline \multirow[t]{5}{*}{ Hypermethylation, promoter region } & Tumor recurrence & $\begin{array}{l}\text { CDH13, MLH1, NDRG2, RASSF1A, CGTF, } \\
\text { HOXA genes }\end{array}$ & {$[42,66-68]$} \\
\hline & Tumor progression & $\begin{array}{l}\text { TP73, TP53, CDKN2A, CDKN2B, } \\
\text { CDKN2C, ADAM23, RB1, DAPK1, VHL, } \\
\text { ER, RUNX3, DCL1, HIF, WNK2, NDRG2, } \\
\text { HOXA genes, TIMP3, FOXM1 Inhibitors }\end{array}$ & {$[42,47,66,67]$} \\
\hline & Angiogenesis & HIF, THBS1 & {$[42,66,67]$} \\
\hline & Higher grade & $\begin{array}{l}\text { MAL2, RASSF1A, IGF2BP1, PDCD1, Aber- } \\
\text { rant CpG Islands, DNMT-3B, GSTP1 }\end{array}$ & {$[42,67-69]$} \\
\hline & Longer survival & MGMT & {$[42]$} \\
\hline \multirow[t]{3}{*}{ Dysregulation } & Higher grade & UPA, ALPL & {$[42]$} \\
\hline & Tumor recurrence & TMEM30B, TGFBeta—LMO4, & {$[66]$} \\
\hline & Tumor progression & CTNNB1, ALPL, IGFBP3, NOTCH & {$[66]$} \\
\hline \multirow[t]{3}{*}{ Abnormal LNCRNA expression } & Tumor progression & $\begin{array}{l}\text { LINC00702, SNHG1, Downregulation } \\
\text { MEG3, LINC00460 }\end{array}$ & {$[70-73]$} \\
\hline & Tumor recurrence & HIST1H1C & {$[66]$} \\
\hline & Higher grade & LINC00702 & [71] \\
\hline \multirow[t]{4}{*}{ Abnormal miRNA expression } & Tumor progression & miR-29c-3p, miR-190a, miR-21, miR-335 & {$[42,67,74]$} \\
\hline & Recurrence & $\begin{array}{l}\text { miR-190a, Downregulation of miR-219c-5, } \\
\text { miR-96-5p, miRNA-224 }\end{array}$ & {$[42,74]$} \\
\hline & Higher grade & $\begin{array}{l}\text { Downregulated miR-145, miR218, miR-34a, } \\
\text { miRNA-224 }\end{array}$ & {$[42,67]$} \\
\hline & Lower grade & miR-107 & {$[42]$} \\
\hline \multirow[t]{5}{*}{ Histone modification } & Recurrence & $\begin{array}{l}\text { Loss of trimethylation of lysine } 27 \text { of His- } \\
\text { tone } 3\end{array}$ & [72] \\
\hline & Worse outcome & $\begin{array}{l}\text { Loss of trimethylation of lysine } 27 \text { of His- } \\
\text { tone3 }\end{array}$ & [75] \\
\hline & Tumor progression & $\begin{array}{l}\text { NAT2 acetyltransferase, EZH2 downregula- } \\
\text { tion }\end{array}$ & {$[69,76]$} \\
\hline & $\begin{array}{l}\text { Disturbed chromatin regulation in grade I } \\
\text { and grade } 3 \text { tumors }\end{array}$ & KDM5C & {$[67,77]$} \\
\hline & Disturbed chromatin regulation in grade 2 & KDM6A & {$[67,77]$} \\
\hline \multirow[t]{2}{*}{ Abnormal SnoRNA expression } & Higher grade & SNORA46, SNORA48 & [78] \\
\hline & Tumor progression & SNORD50A & [78] \\
\hline
\end{tabular}

has yet to be defined [19, 41], evidence points to important interplays. A recent study investigating the epigenomics of clear cell meningiomas found a unique SMARCE1 mutation signature [19], bridging mutations in SMARCE1 to the observed epigenomic changes. Hypomethylation has also been associated with increased aggressiveness of some tumors [46].

DNA methylation patterns can differentiate NF2-mutant from non-NF2 mutant tumors, with further differentiation of non- NF2 mutant tumors into atypical versus "benign." In de novo formation of atypical NF2-mutant meningiomas, hypermethylation is either associated with large-scale CNVs, or gained due to SMARCB1 co-mutations [20]. Separately, "high" methylation levels were found in tumors from older patients, those with increased somatic mutation burden, higher tumor grade, convexity location, and NF2 mutations
[47]. FOXM1 expression, of which $N F 2$ is a negative regulator, is increased with FOXM1/Wnt signaling pathway activation, which likely underlies enhanced cell proliferation [47].

Histone modification and microRNAs (miRNAs) are important in meningioma pathophysiology. Trimethylation of lysine 27 of histone $\mathrm{H} 3$ (H3K27me3) predicts worse outcomes and faster recurrence for grade I/II meningiomas [48]. EZH2, the catalytic subunit of the Polycomb Repressive Complex 2 (PRC2), is thought to mediate this effect by causing longterm gene expression silencing. Using ChIP-seq, we demonstrated H3K27me3 profiles differentiate atypical and benign meningiomas, with increased $\mathrm{H} 3 \mathrm{~K} 27 \mathrm{me} 3$ signal in atypical tumors [20]. In a separate study, NF2 and SUFU mutations were found enriched among tumors lacking H3K27me3 [49]. miRNA expression levels differ between tumor and normal cells, and between atypical and anaplastic meningiomas [50]. 
For example, miRNA-107 acts as a tumor suppressor and is decreased in higher grade lesions, while miRNA-21 acts as an anti-apoptotic factor and its expression is reported to be increased in meningiomas [51].

\section{Pathways to malignancy}

Genetic markers of meningioma aggressiveness is an active area of investigation, aiming to identify molecular signatures for patients at risk of transformation. Unique mutations are being discovered in rarer, more malignant subsets of meningiomas. TERT promoter mutations are associated with recurrence as well as progression to higher grades [52]. The breast cancer (BRCA)1-associated protein-1 tumor suppressor gene $(B A P 1)$ has been linked to a clinically aggressive rhabdoid subtype [53] and both germline and somatic mutations in BAPl predict faster recurrence [54]. As discussed above, DNA methylation correlates with aggressiveness and H3K27me3 loss identifies a subset of grade 2 meningiomas with increased recurrence risk [48]. Gene co-expression analysis is also being used to predict tumor behavior using meta-gene markers. One recent co-expression module identified, E2F4/FOXM1, predicts increased meningioma aggressiveness [55], correlating with previous identification of $F O X M 1$ and $E 2 F 2$ expression networks activated in atypical meningiomas [20]. Further insight into genetic alterations and gene co-expression networks will improve our ability to predict tumor behavior.

\section{Integrated diagnosis}

The newly released WHO Classification of Tumors of the Central Nervous System 2021 updated meningioma grading parameters, including introducing several of these biomarkers. Meningiomas remain a single entity with 15 subtypes; however, criteria defining atypical (grade II) or anaplastic (grade III) are applied regardless of subtype. Subtypes with higher recurrence rates, such as chordoid and clear cell, are considered grade 2 tumors; however, note is made of the need for improved understanding of prognostic markers for these atypical meningiomas. Mutations in SMARCE1, BAP1, KLF4/TRAF7, TERT promoter, and CDKN2A/B deletion, $\mathrm{H} 3 \mathrm{~K} 27 \mathrm{me} 3$ loss and methylation profiling are now officially associated with the classification and grading of meningiomas [7].

\section{Clinical \& treatment implications}

\section{Guidance of patient management decisions}

Management of meningiomas is typically based on location and symptomatology. For small, asymptomatic tumors, patients can be followed with imaging to monitor growth. Larger and/or symptomatic lesions can undergo surgical resection, with possible adjuvant radiotherapy. Prediction of tumor behavior through genomic mutation analysis is beginning to guide clinical decisions. Increasingly, predictive scores are being developed based on integrated transcriptome data [56], and grading systems are being proposed based on epigenomic modifications and chromosomal variations [33, 57]. One DNA methylation-based classification identified low grade, "benign" tumors, with high, rapid recurrence risk, and conversely, higher grade tumors with lower risk. Further, unsupervised clustering differentiated meningiomas from other extra-axial tumors, and determined distinct, clinically-relevant classes predicting recurrence [57]. Another study using DNA methylation profiles developed a methylome-based five-year recurrence-free survival prediction model demonstrating improved recurrence predictions compared to clinical or pathology grading-based systems [58]. Driver et al. developed a three-tiered integrated grading (grades 1-3) incorporating mitotic count and loss of chromosomes 1p, 3p, 4, 6, 10, 14q, 18, 19, or CDKN2A, and demonstrated that this grading scheme improves the current WHO system in predicting progression-free survival [59]. Furthermore, Patel et al. identified three groups using RNAsequencing and whole-exome sequencing that correlate with recurrence [60]. Using a multi-omic approach, Nassiri et al. defined integrative molecular groups through combined analysis of DNA somatic copy-number aberrations, DNA somatic point mutations, DNA methylation, and messenger RNA abundance. They identified four molecular groups that independently associated with recurrence-free survival and better predicted time to recurrence than WHO grading [61].

Importantly, genomic characterization informs preoperative and postoperative decision-making through insights about potential tumor behavior and recurrence risk. Our recent work identified aggressive genomic subgroups with mutations in NF2, TRAF7, and $\mathrm{HH}$ and PI3K pathways, are associated with a $\sim 22$ times higher two-year recurrence rate [62]. Separately, chromosome $1 \mathrm{p}$ deletion and $C D K N 2 A / B$ loss are independently associated with early recurrence and higher grade [29, 39]. Therefore, a convexity meningioma, for instance, occuring in a low surgical risk location may be considered for earlier resection, given they are often NF2mutated and demonstrate higher grade, atypical features. Those arising in surgically challenging skull base locations may be considered for close surveillance and debulking, with consideration of earlier adjuvant radiation if confirmed to be an aggressive subtype.

Management of residual and recurrent lesions remains debated, with those demonstrating higher risk typically undergoing radiation and/or repeat surgical resection [63]. However, limits to the number of resections and radiation treatments patients can safely undergo necessitates more 
effective therapeutic options. Identification of unique driver mutations and advancements in molecular profiling are opening new avenues for targeted, pharmaceutical therapies and allowing implementation of patient-centered treatment protocols.

\section{Development of targeted therapies and precision oncological care for meningioma}

Multiple clinical trials targeting genetic mutations are underway. One promising target is the mTOR pathway, of which NF2 is a negative regulator. Studies investigating mTOR inhibition using Everolimus (NCT01880749, NCT01419639), Everolimus + Octreotide (NCT02333565), or Vistusertib (AZD2014) (NCT03071874, NCT02831257), are showing promising results in progression free survival and tumor volume [64]. Vismodegib (SMO inhibitor) and GSK2256098 (FAK inhibitor) are being used in meningiomas with HH pathway (SMO) or NF2 pathway (FAK) mutations, respectively (NCT02523014).

A phase I study of Alpelisib and Trametinib, PI3K and MEK inhibitors, respectively (NCT03631953), via a combinational approach (inclusion criteria does not include genomic events associated with PI3K activation) in aggressive and recurrent meningiomas is underway. Ribociclib, a cyclin-dependent kinase (CDK) inhibitor, targeting chromosomal abnormalities in the p53/pRB pathway, which is increased in higher grade tumors, is being used in grade II-III meningiomas (NCT02933736) [65]. In addition, clinical trials are investigating the role of radiotherapy, immunotherapy, or a combination of these therapies as primary and adjuvant treatment of meningiomas (see "Appendix" for NCT numbers).

In addition to developing new pharmacological targets, genomic characterization of meningiomas is improving our diagnostic capabilities. Youngblood, et al. used machine learning algorithms to predict underlying genomic events (NF2 vs. non-NF2) based on clinical and imaging features [6]. The ability to use non-invasive analysis to predict tumor genetics, and therefore behavior, will provide invaluable phenotypic meningioma profiles to guide treatment and management decisions without invasive procedures.

\section{Conclusions}

Though meningiomas are frequently considered "benign," morbidity and therapeutic challenges are often encountered, calling this classification into question. As we continue to develop a deeper understanding of the genomic and epigenomic landscape of meningiomas, associated pathophysiological mechanisms suggest a more heterogeneous group than initially thought, with variable clinical behavior, aggressiveness, and recurrence rates. Incorporating genomic and molecular features with histopathological characteristics is improving our diagnostic accuracy and suggesting new, targetable pathways for pharmaceutical interventions. As our understanding of meningioma genomics deepens, our ability to further personalize medical and surgical management of patients with meningiomas will continue to improve, as will our ability to offer targeted therapies and advanced precision oncological care.

\section{Appendix}

Radiotherapy Clinical Trials NCT01166321, NCT02978677, NCT03180268, NCT01795300, NCT02693990, NCT01117844, NCT04127760, NCT00626730, NCT00895622, NCT02594709, NCT04278118, NCT03604978, NCT03267836, NCT04659811.

Iimmunotherapy Clinical Trials NCT02648997, NCT03279692, NCT04728568, NCT04501705, NCT03016091, NCT03604978, NCT03267836, NCT04659811.

Author contributions SMR, SV, AN, SV, and JM developed the idea and structure of the article, SMR, SV, AN, and EG performed the literature and analysis, SMR, SV, AN, SV, EZE, MG, and JM drafted the intial article, and SMR, MWY, LJ, NM, EZE, MG, and JM critically revise the work. All authors have read and approved the manuscript.

Funding This study was funded by the Connecticut Brain Tumor Alliance.

\section{Declarations}

Conflict of interest The authors have no conflicts of interest to declare that are relevant to the content of this article.

Open Access This article is licensed under a Creative Commons Attribution 4.0 International License, which permits use, sharing, adaptation, distribution and reproduction in any medium or format, as long as you give appropriate credit to the original author(s) and the source, provide a link to the Creative Commons licence, and indicate if changes were made. The images or other third party material in this article are included in the article's Creative Commons licence, unless indicated otherwise in a credit line to the material. If material is not included in the article's Creative Commons licence and your intended use is not permitted by statutory regulation or exceeds the permitted use, you will need to obtain permission directly from the copyright holder. To view a copy of this licence, visit http://creativecommons.org/licenses/by/4.0/.

\section{References}

1. Miller KD, Ostrom QT, Kruchko C, Patil N, Tihan T, Cioffi G, Fuchs HE, Waite KA, Jemal A, Siegel RL, Barnholtz-Sloan JS 
(2021) Brain and other central nervous system tumor statistics, 2021. CA Cancer J Clin 71(5):381-406

2. Ostrom QT, Patil N, Cioffi G, Waite K, Kruchko C, BarnholtzSloan JS (2020) CBTRUS statistical report: primary brain and other central nervous system tumors diagnosed in the United States in 2013-2017. Neuro Oncol 22(12 Suppl 2):iv1-iv96

3. Maier H, Ofner D, Hittmair A, Kitz K, Budka H (1992) Classic, atypical, and anaplastic meningioma: three histopathological subtypes of clinical relevance. J Neurosurg 77(4):616-623

4. Louis DN, Perry A, Reifenberger G, Von Deimling A, FigarellaBranger D, Cavenee WK, Ohgaki H, Wiestler OD, Kleihues P, Ellison DW (2016) The 2016 World Health Organization classification of tumors of the central nervous system: a summary. Acta Neuropathol 131(6):803-820

5. Corniola MV, Lemee JM, Meling TR (2020) Histological transformation in recurrent WHO grade I meningiomas. Sci Rep 10(1): 11220

6. Youngblood MW, Duran D, Montejo JD, Li C, Omay SB, Ozduman K, Sheth AH, Zhao AY, Tyrtova E, Miyagishima DF, Fomchenko EI, Hong CS, Clark VE, Riche M, Peyre M, Boetto J, Sohrabi S, Koljaka S, Baranoski JF, Knight J, Zhu H, Pamir MN, Avsar T, Kilic T, Schramm J, Timmer M, Goldbrunner R, Gong Y, Bayri Y, Amankulor N, Hamilton RL, Bilguvar K, Tikhonova I, Tomak PR, Huttner A, Simon M, Krischek B, Kalamarides M, Erson-Omay EZ, Moliterno J, Gunel M (2019) Correlations between genomic subgroup and clinical features in a cohort of more than 3000 meningiomas. J Neurosurg 135(5):1345-1354

7. Louis DN, Perry A, Wesseling P, Brat DJ, Cree IA, FigarellaBranger D, Hawkins C, Ng HK, Pfister SM, Reifenberger G, Soffietti R, von Deimling A, Ellison DW (2021) The 2021 WHO Classification of Tumors of the Central Nervous System: a summary. Neuro Oncol 23(8):1231-1251

8. Kerr K, Qualmann K, Esquenazi Y, Hagan J, Kim DH (2018) Familial syndromes involving meningiomas provide mechanistic insight into sporadic disease. Neurosurgery 83(6):1107-1118

9. Clark VE, Harmanci AS, Bai H, Youngblood MW, Lee TI, Baranoski JF, Ercan-Sencicek AG, Abraham BJ, Weintraub AS, Hnisz D, Simon M, Krischek B, Erson-Omay EZ, Henegariu O, CarrionGrant G, Mishra-Gorur K, Duran D, Goldmann JE, Schramm J, Goldbrunner R, Piepmeier JM, Vortmeyer AO, Gunel JM, Bilguvar K, Yasuno K, Young RA, Gunel M (2016) Recurrent somatic mutations in POLR2A define a distinct subset of meningiomas. Nat Genet 48(10):1253-1259

10. Clark VE, Erson-Omay EZ, Serin A, Yin J, Cotney J, Ozduman K, Avsar T, Li J, Murray PB, Henegariu O, Yilmaz S, Gunel JM, Carrion-Grant G, Yilmaz B, Grady C, Tanrikulu B, Bakircioglu M, Kaymakcalan H, Caglayan AO, Sencar L, Ceyhun E, Atik AF, Bayri Y, Bai H, Kolb LE, Hebert RM, Omay SB, MishraGorur K, Choi M, Overton JD, Holland EC, Mane S, State MW, Bilguvar K, Baehring JM, Gutin PH, Piepmeier JM, Vortmeyer A, Brennan CW, Pamir MN, Kilic T, Lifton RP, Noonan JP, Yasuno K, Gunel M (2013) Genomic analysis of non-NF2 meningiomas reveals mutations in TRAF7, KLF4, AKT1, and SMO. Science 339(6123):1077-1080

11. Brastianos PK, Horowitz PM, Santagata S, Jones RT, McKenna A, Getz G, Ligon KL, Palescandolo E, Van Hummelen P, Ducar MD (2013) Genomic sequencing of meningiomas identifies oncogenic SMO and AKT1 mutations. Nat Genet 45(3):285-289

12. Ruttledge MH, Sarrazin J, Rangaratnam S, Phelan CM, Twist E, Merel P, Delattre O, Thomas G, Nordenskjold M, Collins VP et al (1994) Evidence for the complete inactivation of the NF2 gene in the majority of sporadic meningiomas. Nat Genet 6(2):180-184

13. Nazem AA, Ruzevick J, Ferreira MJ Jr (2020) Advances in meningioma genomics, proteomics, and epigenetics: insights into biomarker identification and targeted therapies. Oncotarget 11(49):4544
14. Agnihotri S, Suppiah S, Tonge PD, Jalali S, Danesh A, Bruce JP, Mamatjan Y, Klironomos G, Gonen L, Au K (2017) Therapeutic radiation for childhood cancer drives structural aberrations of NF2 in meningiomas. Nat Commun 8(1):1-7

15. Zhao AY, Youngblood MW, Erson-Omay EZ, Moliterno J, Gunel M (2020) The genomic landscape of meningiomas. In: Meningiomas. Springer, pp 35-55

16. Jin L, Youngblood MW, Gupte TP, Vetsa S, Nadar A, Barak T, Yalcin K, Aguilera SM, Mishra-Gorur K, Blondin NA, Gorelick E, Omay SB, Pointdujour-Lim R, Judson BL, Alperovich M, Aboian MS, McGuone D, Gunel M, Erson-Omay Z, Fulbright RK, Moliterno J (2021) Type of bony involvement predicts genomic subgroup in sphenoid wing meningiomas. J Neurooncol 154(2):237-246

17. Gupte TP, Li C, Jin L, Yalcin K, Youngblood MW, Miyagishima DF, Mishra-Gorur K, Zhao AY, Antonios J, Huttner A, McGuone D, Blondin NA, Contessa JN, Zhang Y, Fulbright RK, Gunel M, Erson-Omay Z, Moliterno J (2020) Clinical and genomic factors associated with seizures in meningiomas. $\mathrm{J}$ Neurosurg 1:1-10

18. Smith MJ (2015) Germline and somatic mutations in meningiomas. Cancer Genet 208(4):107-114

19. Sievers P, Sill M, Blume C, Tauziede-Espariat A, Schrimpf D, Stichel D, Reuss DE, Dogan H, Hartmann C, Mawrin C (2021) Clear cell meningiomas are defined by a highly distinct DNA methylation profile and mutations in SMARCE1. Acta Neuropathol 141(2):281-290

20. Harmanci AS, Youngblood MW, Clark VE, Coskun S, Henegariu O, Duran D, Erson-Omay EZ, Kaulen LD, Lee TI, Abraham BJ, Simon M, Krischek B, Timmer M, Goldbrunner R, Omay SB, Baranoski J, Baran B, Carrion-Grant G, Bai H, Mishra-Gorur K, Schramm J, Moliterno J, Vortmeyer AO, Bilguvar K, Yasuno K, Young RA, Gunel M (2017) Integrated genomic analyses of de novo pathways underlying atypical meningiomas. Nat Commun 8:14433

21. Reuss DE, Piro RM, Jones DT, Simon M, Ketter R, Kool M, Becker A, Sahm F, Pusch S, Meyer J (2013) Secretory meningiomas are defined by combined KLF4 K409Q and TRAF7 mutations. Acta Neuropathol 125(3):351-358

22. Boetto J, Apra C, Bielle F, Peyre M, Kalamarides M (2018) Selective vulnerability of the primitive meningeal layer to prenatal Smo activation for skull base meningothelial meningioma formation. Oncogene 37(36):4955-4963

23. Boetto J, Bielle F, Sanson M, Peyre M, Kalamarides M (2017) SMO mutation status defines a distinct and frequent molecular subgroup in olfactory groove meningiomas. Neuro Oncol 19(3):345-351

24. Smith MJ, Wallace AJ, Bennett C, Hasselblatt M, Elert-Dobkowska E, Evans LT, Hickey WF, Van Hoff J, Bauer D, Lee A (2014) Germline SMARCE1 mutations predispose to both spinal and cranial clear cell meningiomas. J Pathol 234(4):436-440

25. Gill CM, Loewenstern J, Rutland JW, Arib H, Pain M, Umphlett M, Kinoshita Y, McBride RB, Bederson J, Donovan M, Sebra R, Fowkes M, Shrivastava RK (2021) SWI/SNF chromatin remodeling complex alterations in meningioma. J Cancer Res Clin Oncol

26. Sahm F, Schrimpf D, Olar A, Koelsche C, Reuss D, Bissel J, Kratz A, Capper D, Schefzyk S, Hielscher T (2016) TERT promoter mutations and risk of recurrence in meningioma. J Natl Cancer Inst 108(5):djv377

27. Ueki K, Wen-Bin C, Narita Y, Asai A, Kirino T (1999) Tight association of loss of merlin expression with loss of heterozygosity at chromosome $22 \mathrm{q}$ in sporadic meningiomas. Cancer Res 59(23):5995-5998

28. Gabeau-Lacet D, Engler D, Gupta S, Scangas GA, Betensky RA, Barker FG 2nd, Loeffler JS, Louis DN, Mohapatra G (2009) Genomic profiling of atypical meningiomas associates gain 
of 1q with poor clinical outcome. J Neuropathol Exp Neurol 68(10):1155-1165

29. Suppiah S, Nassiri F, Bi WL, Dunn IF, Hanemann CO, Horbinski CM, Hashizume R, James CD, Mawrin C, Noushmehr H (2019) Molecular and translational advances in meningiomas. Neuro Oncol 21(Suppl 1):i4-i17

30. Lamszus K (2004) Meningioma pathology, genetics, and biology. J Neuropathol Exp Neurol 63(4):275-286

31. Mawrin C, Perry A (2010) Pathological classification and molecular genetics of meningiomas. J Neurooncol 99(3):379-391

32. Olar A, Wani KM, Wilson CD, Zadeh G, DeMonte F, Jones DT, Pfister SM, Sulman EP, Aldape KD (2017) Global epigenetic profiling identifies methylation subgroups associated with recurrencefree survival in meningioma. Acta Neuropathol 133(3):431-444

33. Ma J, Hong Y, Chen W, Li D, Tian K, Wang K, Yang Y, Zhang Y, Chen Y, Song L (2020) High copy-number variation burdens in cranial meningiomas from patients with diverse clinical phenotypes characterized by hot genomic structure changes. Front Oncol 10:1382

34. Hemmer S, Urbschat S, Oertel J, Ketter R (2019) Deletions in the $17 \mathrm{q}$ chromosomal region and their influence on the clonal cytogenetic evolution of recurrent meningiomas. Mol Cytogenet 12(1): $1-8$

35. Juratli TA, McCabe D, Nayyar N, Williams EA, Silverman IM, Tummala SS, Fink AL, Baig A, Martinez-Lage M, Selig MK (2018) DMD genomic deletions characterize a subset of progressive/higher-grade meningiomas with poor outcome. Acta Neuropathol 136(5):779-792

36. Abedalthagafi MS, Merrill PH, Bi WL, Jones RT, Listewnik ML, Ramkissoon SH, Thorner AR, Dunn IF, Beroukhim R, Alexander BM (2014) Angiomatous meningiomas have a distinct genetic profile with multiple chromosomal polysomies including polysomy of chromosome 5. Oncotarget 5(21):10596

37. Lee YS, Lee YS (2020) Molecular characteristics of meningiomas. J Pathol Transl Med 54(1):45

38. Guyot A, Duchesne M, Robert S, Lia AS, Derouault P, Scaon E, Lemnos L, Salle H, Durand K, Labrousse F (2019) Analysis of CDKN2A gene alterations in recurrent and non-recurrent meningioma. J Neurooncol 145(3):449-459

39. Sievers P, Hielscher T, Schrimpf D, Stichel D, Reuss DE, Berghoff AS, Neidert MC, Wirsching HG, Mawrin C, Ketter R, Paulus W, Reifenberger G, Lamszus K, Westphal M, Etminan N, Ratliff M, Herold-Mende C, Pfister SM, Jones DTW, Weller M, Harter PN, Wick W, Preusser M, von Deimling A, Sahm F (2020) CDKN2A/B homozygous deletion is associated with early recurrence in meningiomas. Acta Neuropathol 140(3):409-413

40. Bello MJ, Aminoso C, Lopez-Marin I, Arjona D, GonzalezGomez P, Alonso ME, Lomas J, de Campos JM, Kusak ME, Vaquero J, Isla A, Gutierrez M, Sarasa JL, Rey JA (2004) DNA methylation of multiple promoter-associated $\mathrm{CpG}$ islands in meningiomas: relationship with the allelic status at $1 \mathrm{p}$ and 22q. Acta Neuropathol 108(5):413-421

41. Shen L, Lin D, Cheng L, Tu S, Wu H, Xu W, Pan Y, Wang X, Zhang J, Shao A (2020) Is DNA methylation a ray of sunshine in predicting meningioma prognosis? Front Oncol 10

42. Venza M, Visalli M, Beninati C, Catalano T, Biondo C, Teti D, Venza I (2015) Involvement of epimutations in meningioma. Brain Tumor Pathol 32(3):163-168

43. Di Vinci A, Brigati C, Casciano I, Banelli B, Borzì L, Forlani A, Ravetti GL, Allemanni G, Melloni I, Zona G (2012) HOXA7, 9, and 10 are methylation targets associated with aggressive behavior in meningiomas. Transl Res 160(5):355-362

44. Kishida Y, Natsume A, Kondo Y, Takeuchi I, An B, Okamoto Y, Shinjo K, Saito K, Ando H, Ohka F (2012) Epigenetic subclassification of meningiomas based on genome-wide DNA methylation analyses. Carcinogenesis 33(2):436-441

45. Ando H, Natsume A, Iwami K, Ohka F, Kuchimaru T, KizakaKondoh S, Ito K, Saito K, Sugita S, Hoshino T (2013) A hypoxiainducible factor (HIF)- $3 \alpha$ splicing variant, HIF-3 $\alpha 4$ impairs angiogenesis in hypervascular malignant meningiomas with epigenetically silenced HIF- $3 \alpha 4$. Biochem Biophys Res Commun 433(1):139-144

46. Kandenwein JA, Park-Simon T-W, Schramm J, Simon M (2011) uPA/PAI-1 expression and uPA promoter methylation in meningiomas. J Neurooncol 103(3):533-539

47. Vasudevan HN, Braunstein SE, Phillips JJ, Pekmezci M, Tomlin BA, Wu A, Reis GF, Magill ST, Zhang J, Feng FY, Nicholaides T, Chang SM, Sneed PK, McDermott MW, Berger MS, Perry A, Raleigh DR (2018) Comprehensive molecular profiling identifies FOXM1 as a key transcription factor for meningioma proliferation. Cell Rep 22(13):3672-3683

48. Nassiri F, Wang JZ, Singh O, Karimi S, Dalcourt T, Ijad N, Pirouzmand N, Ng H-K, Saladino A, Pollo B (2021) Loss of $\mathrm{H} 3 \mathrm{~K} 27 \mathrm{me} 3$ in meningiomas. Neuro-oncology

49. Katz LM, Hielscher T, Liechty B, Silverman J, Zagzag D, Sen R, Wu P, Golfinos JG, Reuss D, Neidert MC, Wirsching HG, Baumgarten P, Herold-Mende C, Wick W, Harter PN, Weller M, von Deimling A, Snuderl M, Sen C, Sahm F (2018) Loss of histone H3K27me3 identifies a subset of meningiomas with increased risk of recurrence. Acta Neuropathol 135(6):955-963

50. Kliese N, Gobrecht P, Pachow D, Andrae N, Wilisch-Neumann A, Kirches E, Riek-Burchardt M, Angenstein F, Reifenberger G, Riemenschneider MJ (2013) miRNA-145 is downregulated in atypical and anaplastic meningiomas and negatively regulates motility and proliferation of meningioma cells. Oncogene 32(39):4712-4720

51. Katar S, Baran O, Evran S, Cevik S, Akkaya E, Baran G, Antar V, Hanimoglu H, Kaynar MY (2017) Expression of miRNA-21, miRNA-107, miRNA-137 and miRNA-29b in meningioma. Clin Neurol Neurosurg 156:66-70

52. Goutagny S, Nault JC, Mallet M, Henin D, Rossi JZ, Kalamarides M (2014) High incidence of activating TERT promoter mutations in meningiomas undergoing malignant progression. Brain Pathol 24(2):184-189

53. Shankar GM, Santagata S (2017) BAP1 mutations in highgrade meningioma: implications for patient care. Neuro Oncol 19(11):1447-1456

54. Shankar GM, Abedalthagafi M, Vaubel RA, Merrill PH, Nayyar N, Gill CM, Brewster R, Bi WL, Agarwalla PK, Thorner AR, Reardon DA, Al-Mefty O, Wen PY, Alexander BM, van Hummelen P, Batchelor TT, Ligon KL, Ligon AH, Meyerson M, Dunn IF, Beroukhim R, Louis DN, Perry A, Carter SL, Giannini C, Curry WT Jr, Cahill DP, Barker FG 2nd, Brastianos PK, Santagata S (2017) Germline and somatic BAP1 mutations in high-grade rhabdoid meningiomas. Neuro Oncol 19(4):535-545

55. Zador Z, Landry AP, Saha A, Cusimano MD (2020) Gene expression signatures identify biologically homogenous subgroups of grade 2 meningiomas. Front Oncol 10:541928

56. Liu F, Qian J, Ma C (2021) MPscore: a novel predictive and prognostic scoring for progressive meningioma. Cancers 13(5):1113

57. Sahm F, Schrimpf D, Stichel D, Jones DT, Hielscher T, Schefzyk S, Okonechnikov K, Koelsche C, Reuss DE, Capper D (2017) DNA methylation-based classification and grading system for meningioma: a multicentre, retrospective analysis. Lancet Oncol 18(5):682-694

58. Nassiri F, Mamatjan Y, Suppiah S, Badhiwala JH, Mansouri S, Karimi S, Saarela O, Poisson L, Gepfner-Tuma I, Schittenhelm J, Ng HK, Noushmehr H, Harter P, Baumgarten P, Weller M, Preusser M, Herold-Mende C, Tatagiba M, Tabatabai G, Sahm F, von Deimling A, M. International Consortium on, Zadeh 
G, Aldape KD (2019) DNA methylation profiling to predict recurrence risk in meningioma: development and validation of a nomogram to optimize clinical management. Neuro Oncol 21(7):901-910

59. Driver J, Hoffman SE, Tavakol S, Woodward E, Maury EA, Bhave V, Greenwald NF, Nassiri F, Aldape K, Zadeh G, Choudhury A, Vasudevan HN, Magill ST, Raleigh DR, Abedalthagafi M, Aizer AA, Alexander BM, Ligon KL, Reardon DA, Wen PY, Al-Mefty O, Ligon AH, Dubuc AM, Beroukhim R, Claus EB, Dunn IF, Santagata S, Bi WL (2021) A molecularly integrated grade for meningioma. Neuro-oncology

60. Patel AJ, Wan YW, Al-Ouran R, Revelli JP, Cardenas MF, Oneissi M, Xi L, Jalali A, Magnotti JF, Muzny DM, Doddapaneni H, Sebastian S, Heck KA, Goodman JC, Gopinath SP, Liu Z, Rao G, Plon SE, Yoshor D, Wheeler DA, Zoghbi HY, Klisch TJ (2019) Molecular profiling predicts meningioma recurrence and reveals loss of DREAM complex repression in aggressive tumors. Proc Natl Acad Sci USA 116(43):21715-21726

61. Nassiri F, Liu J, Patil V, Mamatjan Y, Wang JZ, Hugh-White R, Macklin AM, Khan S, Singh O, Karimi S, Corona RI, Liu LY, Chen CY, Chakravarthy A, Wei Q, Mehani B, Suppiah S, Gao A, Workewych AM, Tabatabai G, Boutros PC, Bader GD, de Carvalho DD, Kislinger T, Aldape K, Zadeh G (2021) A clinically applicable integrative molecular classification of meningiomas. Nature 597(7874):119-125

62. Youngblood MW, Miyagishima DF, Jin L, Gupte T, Li C, Duran D, Montejo JD, Zhao A, Sheth A, Tyrtova E (2021) Associations of meningioma molecular subgroup and tumor recurrence. Neuro Oncol 23(5):783-794

63. Hong CS, Moliterno J (2020) Surgical considerations for newly diagnosed meningiomas. In: Meningiomas. Springer, pp 75-96

64. Graillon T, Sanson M, Campello C, Idbaih A, Peyre M, Peyrière H, Basset N, Autran D, Roche C, Kalamarides M (2020) Everolimus and octreotide for patients with recurrent meningioma: results from the phase II CEVOREM trial. Clin Cancer Res 26(3):552-557

65. Juric V, Murphy B (2020) Cyclin-dependent kinase inhibitors in brain cancer: Current state and future directions. Cancer Drug Resist 3(1):48-62

66. He S, Pham MH, Pease M, Zada G, Giannotta SL, Wang K, Mack WJ (2013) A review of epigenetic and gene expression alterations associated with intracranial meningiomas. Neurosurg Focus 35(6):E5

67. Galani V, Lampri E, Varouktsi A, Alexiou G, Mitselou A, Kyritsis AP (2017) Genetic and epigenetic alterations in meningiomas. Clin Neurol Neurosurg 158:119-125

68. San-Miguel T, Navarro L, Megias J, Munoz-Hidalgo L, Gil-Benso R, Roldan P, Lopez-Gines C, Cerda-Nicolas M (2019) Epigenetic changes underlie the aggressiveness of histologically benign meningiomas that recur. Hum Pathol 84:105-114

69. Samal S, Patnaik A, Sahu F, Purkait S (2020) Altered expression of epigenetic modifiers EZH2, H3K27me3, and DNA methyltransferases in meningiomas - prognostic biomarkers for routine practice. Folia Neuropathol 58(2):133-142

70. Xing H, Wang S, Li Q, Ma Y, Sun P (2018) Long noncoding RNA LINC00460 targets miR-539/MMP-9 to promote meningioma progression and metastasis. Biomed Pharmacother 105:677-682

71. Li T, Ren J, Ma J, Wu J, Zhang R, Yuan H, Han X (2019) LINC00702/miR-4652-3p/ZEB1 axis promotes the progression of malignant meningioma through activating Wnt/beta-catenin pathway. Biomed Pharmacother 113:108718

72. Zhang Y, Yu R, Li Q, Li Y, Xuan T, Cao S, Zheng J (2020) SNHG1/miR-556-5p/TCF12 feedback loop enhances the tumorigenesis of meningioma through Wnt signaling pathway. J Cell Biochem 121(2):1880-1889

73. Balik V, Srovnal J, Sulla I, Kalita O, Foltanova T, Vaverka M, Hrabalek L, Hajduch M (2013) MEG3: a novel long noncoding potentially tumour-suppressing RNA in meningiomas. J Neurooncol 112(1):1-8

74. Huntoon K, Toland AMS, Dahiya S (2020) Meningioma: a review of clinicopathological and molecular aspects. Front Oncol 10:579599

75. Nassiri F, Wang JZ, Singh O, Karimi S, Dalcourt T, Ijad N, Pirouzmand N, Ng HK, Saladino A, Pollo B, Dimeco F, Yip S, Gao A, Aldape KD, Zadeh G, M. International Consortium on (2021) Loss of H3K27me3 in meningiomas. Neuro Oncol 23(8):1282-1291

76. Olivera M, Martinez C, Molina JA, Alonso-Navarro H, JimenezJimenez FJ, Garcia-Martin E, Benitez J, Agundez JA (2006) Increased frequency of rapid acetylator genotypes in patients with brain astrocytoma and meningioma. Acta Neurol Scand 113(5):322-326

77. Juratli TA, McCabe D, Nayyar N, Williams EA, Silverman IM, Tummala SS, Fink AL, Baig A, Martinez-Lage M, Selig MK, Bihun IV, Shankar GM, Penson T, Lastrapes M, Daubner D, Meinhardt M, Hennig S, Kaplan AB, Fujio S, Kuter BM, Bertalan MS, Miller JJ, Batten JM, Ely HA, Christiansen J, Baretton GB, Stemmer-Rachamimov AO, Santagata S, Rivera MN, Barker FG 2nd, Schackert G, Wakimoto H, Iafrate AJ, Carter SL, Cahill DP, Brastianos PK (2018) DMD genomic deletions characterize a subset of progressive/higher-grade meningiomas with poor outcome. Acta Neuropathol 136(5):779-792

78. Liu J, Xia C, Wang G (2020) Multi-omics analysis in initiation and progression of meningiomas: from pathogenesis to diagnosis. Front Oncol 10:1491

79. Weber RG et al (1997) Analysis of genomic alterations in benign, atypical, and anaplastic meningiomas: toward a genetic model of meningioma progression. Proc Nat Acad Sci 94(26):14719-14724

Publisher's Note Springer Nature remains neutral with regard to jurisdictional claims in published maps and institutional affiliations. 